ARTICLE

https://doi.org/10.1038/s41467-019-11229-2

\title{
Room-temperature superionic-phase nanocrystals synthesized with a twinned lattice
}

\author{
Jianxiao Gong (10) ${ }^{1}$ \& Prashant K. Jain (1) 1,2,3,4
}

The engineering of nanoscale features enables the properties of solid-state materials to be tuned. Here, we show the tunable preparation of cuprous sulfide nanocrystals ranging in internal structures from single-domain to multi-domain. The synthetic method utilizes in-situ oxidation to grow nanocrystals with a controlled degree of copper deficiency. Copperdeficient nanocrystals spontaneously undergo twinning to a multi-domain structure. Nanocrystals with twinned domains exhibit markedly altered crystallographic phase and phase transition characteristics as compared to single-domain nanocrystals. In the presence of twin boundaries, the temperature for transition from the ordered phase to the high-coppermobility superionic phase is depressed. Whereas the superionic phase is stable in the bulk only above ca. $100^{\circ} \mathrm{C}$, cuprous sulfide nanocrystals of ca. $7 \mathrm{~nm}$ diameter and a twinned structure are stable in the superionic phase well below ambient temperature. These findings demonstrate twinning to be a structural handle for nanoscale materials design and enable applications for an earth-abundant mineral in solid electrolytes for Li-S batteries.

\footnotetext{
${ }^{1}$ Department of Chemistry, University of Illinois at Urbana-Champaign, Urbana, IL 61801, USA. ${ }^{2}$ Materials Research Laboratory, University of IIlinois at Urbana-Champaign, Urbana, IL 61801, USA. ${ }^{3}$ Beckman Institute of Advanced Science and Technology, University of Illinois at Urbana-Champaign, Urbana, IL 61801, USA. ${ }^{4}$ Department of Physics, University of Illinois at Urbana-Champaign, Urbana, IL 61801, USA. Correspondence and requests for materials should be addressed to P.K.J. (email: jain@illinois.edu)
} 
C rystal twinning, wherein two separate crystal domains are symmetrically joined via shared lattice positions, is commonly encountered in minerals and industrial materials ${ }^{1}$. Such twin defects influence the structural and mechanical properties of materials $;^{2-5}$ for instance, shock hardening of stainless steel is thought to result from twin boundaries ${ }^{2,3,6}$. Twinning has also been found in metal and semiconductor nanocrystals $(\mathrm{NCs})^{2,4,5,7-11}$, where it has been exploited for the synthesis of anisotropic nanostructures ${ }^{11-13}$, the exploration of structuredependence of catalytic, optical and mechanical properties ${ }^{2,6}$, and the formation of ultrahard materials ${ }^{3,8,11,13}$. We encounter twinning in NCs of copper sulfide $\left(\mathrm{Cu}_{2-x} \mathrm{~S}\right)$.

$\mathrm{Cu}_{2-x} \mathrm{~S}$ is an ionic solid attracting broad interest due to its potential as a solid electrolyte for batteries. The ambienttemperature phase of $\mathrm{Cu}_{2-x} \mathrm{~S}$, called low chalcocite, has low $\mathrm{Cu}^{+}$mobility ${ }^{14}$. Above $104^{\circ} \mathrm{C}$, bulk $\mathrm{Cu}_{2-x} \mathrm{~S}$ transitions to a superionic phase, called high chalcocite, wherein the $\mathrm{Cu}^{+}$form a highly mobile, liquid-like sub-lattice within a rigid, immobile hexagonally close-packed $\mathrm{S}^{2-}$ framework ${ }^{14,15}$. While such superionic phases are promising as solid electrolytes due to their high ion conductance $\left(>10^{-3} \mathrm{~S} \mathrm{~cm}^{-1}\right)^{16}$, the high temperatures required to access superionic phases pose an obstacle for their use in batteries.

Here, we demonstrate that NCs engineered with twinned domains exhibit a superionic phase at temperatures within the safe operating range of batteries. Specifically, we describe a method for the controllable introduction of twin boundaries in $\mathrm{Cu}_{2-x} \mathrm{~S}$ NCs. We find that the twin boundaries thus introduced stabilize the high-temperature superionic form of $\mathrm{Cu}_{2-x} \mathrm{~S}$ in the NCs. In contrast to the bulk, $\mathrm{Cu}_{2-x} \mathrm{~S}$ NCs synthesized with twin boundaries exhibit the superionic phase at a dramatically reduced temperature (as low as $0{ }^{\circ} \mathrm{C}$ ). In general, the findings show that crystal twinning can be employed as a structural handle for tuning ionic structure and transport on the nanoscale.

\section{Results and discussion}

Synthesis of $\mathrm{Cu}_{2-x} \mathrm{~S}$ NCs with controlled $\mathrm{Cu}$ deficiency levels. $\mathrm{Cu}$ deficiency is a salient feature of $\mathrm{Cu}_{2-x} \mathrm{~S}^{17,18}$. In nearstoichiometric $\mathrm{Cu}(\mathrm{II})$ sulfide, $x$ can range from $0-0.07^{14,19,20}$. We synthesized NCs with a controlled Cu-deficiency level. To achieve this, we modified a published synthesis protocol to allow for in situ oxidation (see Methods) ${ }^{21}$. Specifically, a controlled volume of air was injected into the reaction flask. We found that the presence of air during synthesis resulted in the oxidative removal of $\mathrm{Cu}$ from the $\mathrm{Cu}_{2} \mathrm{~S}$ lattice concomitant with the growth of the NCs. As an outcome, the NCs were formed with a $\mathrm{Cu}$ deficient or sub-stoichiometric composition.

The sub-stoichiometry $(x)$ was determined by characterization of the localized surface plasmon resonance (LSPR) of the $\mathrm{NCs}^{22,23}$. Cu deficiencies contribute hole carriers to the valence band. These hole carriers result in the appearance of a LSPR band in the near-infrared region (NIR) of the extinction spectrum of the NC colloid (Fig. 1a). Whereas NCs synthesized in the absence of air exhibit only a weak absorption in the NIR region (Fig. 1a, black curve), NCs synthesized with in situ oxidation exhibit strong LSPR bands manifesting their Cu-deficient compositions. The larger the volume of air injected in the synthesis, the higher was the LSPR peak energy. It is well established that the peak energy, $\omega_{s p}$, is related to the hole carrier density, $N_{\mathrm{h}}$ :

$$
\omega_{\mathrm{sp}}=\sqrt{\frac{N_{\mathrm{h}} e^{2}}{\left(1+2 \varepsilon_{\mathrm{m}}\right) \varepsilon_{0} m_{\mathrm{h}}}-\gamma^{2}}
$$

where $e$ represents the electronic charge, $\varepsilon_{0}$ is the permittivity of free space, $\varepsilon_{\mathrm{m}}$ is the dielectric constant of the medium, $\gamma$ represents the linewidth of the LSPR band, and $m_{\mathrm{h}}$ is the effective hole mass ${ }^{22}$. From the LSPR peak energy $\omega_{\text {sp }}$ and linewidth $\gamma$ of $0.21 \mathrm{eV}$ (ref. ${ }^{22}$ ) and values of $m_{\mathrm{h}}=0.8 m_{0}$ (where $m_{0}$ is the electron mass) ${ }^{24}$ and $\varepsilon_{m}=2.28$ (for tetrachloroethylene) ${ }^{22}, N_{\mathrm{h}}$ a

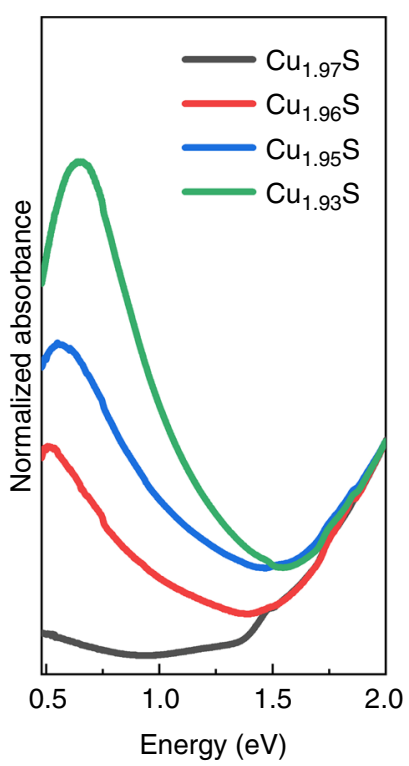

b
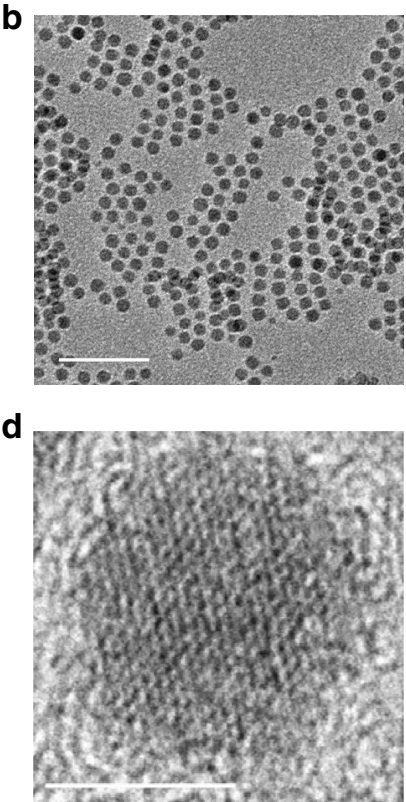

C

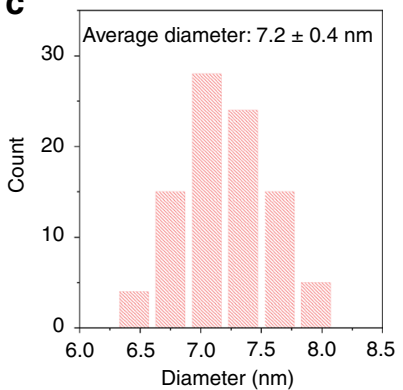

$\mathbf{e}$

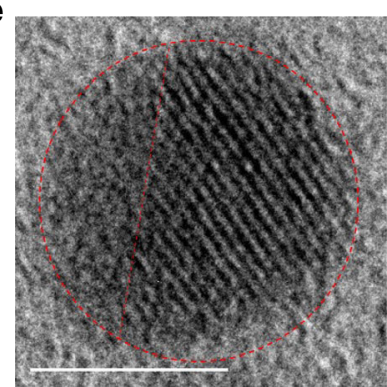

Fig. 1 Characteristics of $\mathrm{Cu}_{2-x} \mathrm{~S} \mathrm{NCs}$ of sub-stoichiometric composition prepared by in-situ air exposure during hot-injection synthesis. a Vis-NIR extinction spectra (normalized to $1 \mathrm{at} 2 \mathrm{eV}$ ) of colloids of $\mathrm{Cu}_{2-x} \mathrm{~S} \mathrm{NCs}$ of four different levels of sub-stoichiometry. Spectra are plotted in terms of energy in eV, which is approximated as $1240 /$ (Wavelength in $\mathrm{nm}$ ). $\mathbf{b}$ A wide-field TEM image (scale bar $=50 \mathrm{~nm}$ ) of $\mathrm{Cu}_{1.97} \mathrm{~S} \mathrm{NCs}$ and $\mathbf{c}$ a histogram showing the NC diameter distribution determined from an analysis of the TEM image. The average diameter of the NCs is determined to be $7.2 \mathrm{~nm}$ with a standard deviation of $0.7 \mathrm{~nm}$. Representative HRTEM image (scale bar $=5 \mathrm{~nm}$ ) of a single NC of $\mathbf{d} \mathrm{Cu}_{1.97} \mathrm{~S}$ and $\mathbf{e} \mathrm{Cu}_{1.93} \mathrm{~S}$. In e the NC boundary is marked by a dotted red circle and the domain boundary is marked by the dotted red line 
$\left(\mathrm{m}^{-3}\right)$ was estimated, which is a direct measure of the $\mathrm{Cu}$ defect density $\delta\left(\mathrm{mol} \mathrm{cm}^{-3}\right)$.

$$
\delta=10^{-6} \frac{N_{\mathrm{h}}}{N_{\mathrm{A}}}
$$

where $N_{\mathrm{A}}$ is Avogadro's number. The level of sub-stoichiometry, $x$, is then obtained as:

$$
x=\delta \frac{M}{\rho}
$$

where $\rho$ is the density of cuprous sulfide with a value of $5.6 \mathrm{~g} \mathrm{~cm}^{-3}$ and $M$ is the formula weight for $\mathrm{Cu}_{2} \mathrm{~S}$ with a value of $159.16 \mathrm{~g}$ $\mathrm{mol}^{-1}$. The resulting relationship between the stoichiometry and the LSPR peak frequency, $\omega_{\mathrm{sp}}$, is best approximated as:

$$
2-x=1.99336-0.15059 \omega_{\mathrm{sp}}^{2}
$$

We estimated the stoichiometry $2-x$ for the four different volumes of air-injection that we employed in our synthesis: $0 \mathrm{~mL}$ of air gave a composition of $\mathrm{Cu}_{1.97} \mathrm{~S}, 0.01 \mathrm{~mL}$ gave $\mathrm{Cu}_{1.96} \mathrm{~S}, 0.1 \mathrm{~mL}$ gave $\mathrm{Cu}_{1.95} \mathrm{~S}$, and $1 \mathrm{~mL}$ gave $\mathrm{Cu}_{1.93} \mathrm{~S}$. Thus, the $\mathrm{Cu}$-deficiency level was controllable by the volume of air introduced. Although, the composition estimated from $\omega_{\text {sp }}$ using the above methodology is not expected to have absolute precision due to the approximations and uncertainties involved ${ }^{22}$, the estimate provides a reliable measure of relative $\mathrm{Cu}$-deficiency level.

Sub-stoichiometry-dependent internal structure of the NCs. From transmission electron microscopy (TEM), the NCs were found to have an average diameter of $7 \mathrm{~nm}$ (Fig. 1b, c), which did not change much with the $\mathrm{Cu}$-deficiency level. However, highresolution TEM (HRTEM) images (Fig. 2 and Supplementary Figs. 1-3) showed a marked difference in the internal structure of the NCs of different Cu-deficiency level. As shown in Fig. 1d, e for representative NCs and summarized in a table in Fig. 2e for a population of over $200 \mathrm{NCs}, \mathrm{Cu}_{1.97} \mathrm{~S} \mathrm{NCs}$ are mainly singledomain, whereas a large fraction of $\mathrm{Cu}_{1.93} \mathrm{~S}$ NCs show the presence of multiple domains. The representative NC shown in Fig. 1e exhibits two domains, one with distinct lattice fringes, while the other domain lacks lattice fringes. Additional examples of $\mathrm{Cu}_{1.93} \mathrm{~S}$ NCs with multiple domains are shown in Fig. $2 \mathrm{a}-\mathrm{d}$ and in Supplementary Fig. 1. While the presence of two domains is most prevalent for this stoichiometry, NCs with three or four domains are also occasionally observed (Fig. 2d and Supplementary Fig. 1). The prevalence of multiple domains follows a systematic trend as a function of the $\mathrm{Cu}$-deficiency level. At a composition of $\mathrm{Cu}_{1.97} \mathrm{~S}$, only 1 of $236 \mathrm{NCs}$ analyzed show multiple domains. At $\mathrm{Cu}_{1.96} \mathrm{~S}, 11$ of $328 \mathrm{NCs}$ exhibit multiple domains. At $\mathrm{Cu}_{1.93} \mathrm{~S}, 115$ of $300 \mathrm{NCs}$ exhibit two domains and a handful show three/four domains.

Domains formed by twinning. The multi-domain structure of the $\mathrm{Cu}_{1.93} \mathrm{~S} \mathrm{NCs}$ is an outcome of crystal twinning, as we found from a crystallographic analysis of the HRTEM images of NCs obtained at two different tilt angles. Results from three representative NCs are shown in Fig. 3. In the first example (Fig. 3a), the NC imaged without a tilt exhibits one domain with lattice fringes (Region 1) and another domain with none (Region 2). When imaged at a tilt of $2.1^{\circ}$, both domains show lattice fringes. The lattices of the two domains exhibit a twinning relationship.

Scanning transmission electron microscopy (STEM)-based three-dimensional 3D tomographic reconstruction would enable atomic-resolution visualization of the twinning in these NCs. However, our attempts at such characterization of the $\mathrm{Cu}_{1.93} \mathrm{~S}$ NCs were unsuccessful, because the NCs exhibited low structural stability under the focused electron beam, making it infeasible to conduct atomic-resolution imaging at a range of orientations. Bright-field TEM imaging, which has been employed for the identification of twinning in nanostructures $2,5,7,8,12,13,25$, proved to be much more informative. Since lattice structures imaged by bright-field TEM can be complicated by the level of defocus, we ascertained the presence of twinning from the reciprocal lattice structure obtained by fast-Fourier transform (FFT) of the realspace HRTEM images (Fig. 3).

The FFT of the full NC contains a reciprocal lattice spot that is split into two, one contributed by each of the domains (Regions 1 and 2). Thus, the lattices of the two domains are rotated with respect to one another and exhibit a mirror image relationship. The twin boundary (TB) between the domains serves as a mirror reflection plane that is common to both domains. The twinning is of non-merohedral type, as indicated by the lack of complete

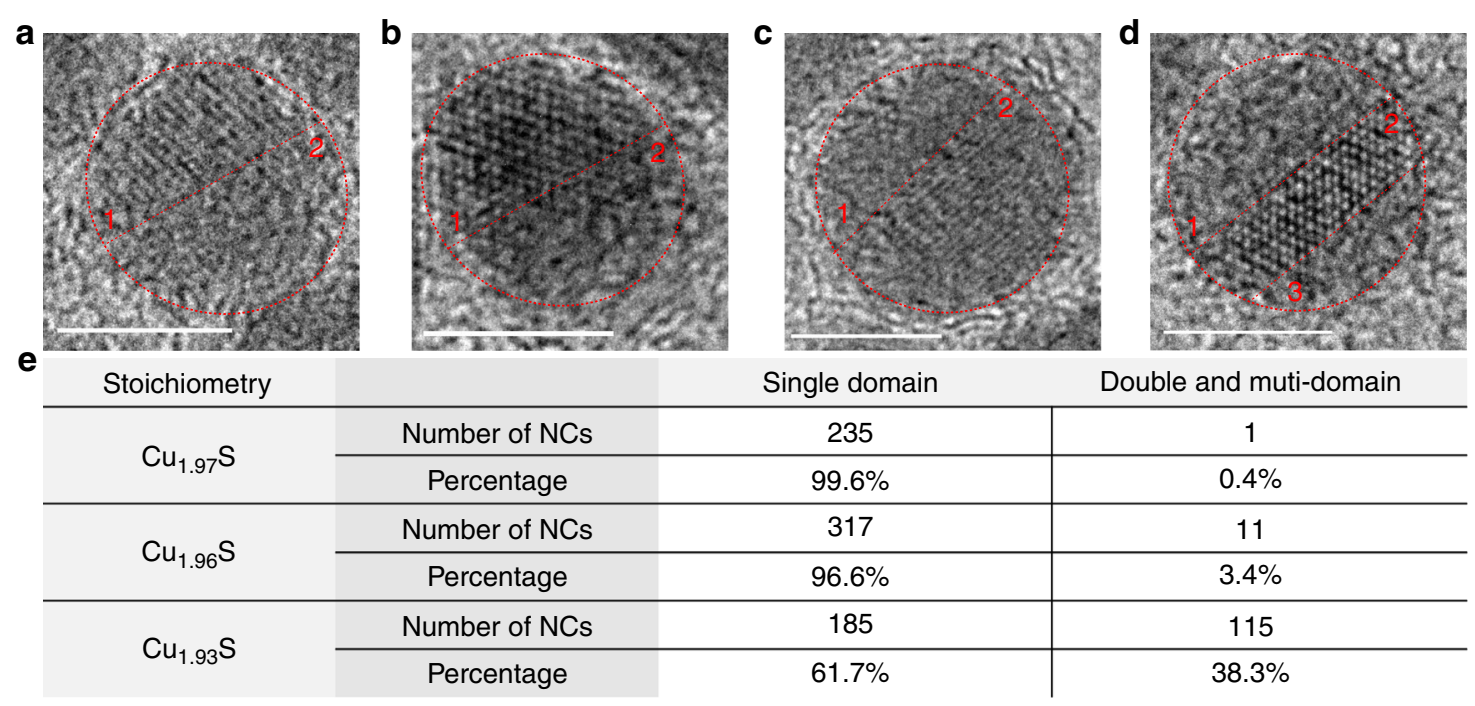

Fig. 2 Internal domain structure. Representative examples of $\mathrm{Cu}_{1.93} \mathrm{~S}$ NCs with multiple domains apparent in HRTEM imaging: NCs exhibiting a-c two domains and $\mathbf{d}$ three domains. In a-d the NC boundary is marked by a dotted red circle and domain boundaries are marked by dotted red lines. Domains are labeled as 1, 2, and 3. All scale bars are $5 \mathrm{~nm}$ in length. e Table of statistics of NCs exhibiting single- or multi-domain structures for three levels of substoichiometry. The statistics were determined by analysis of NCs imaged by HRTEM 


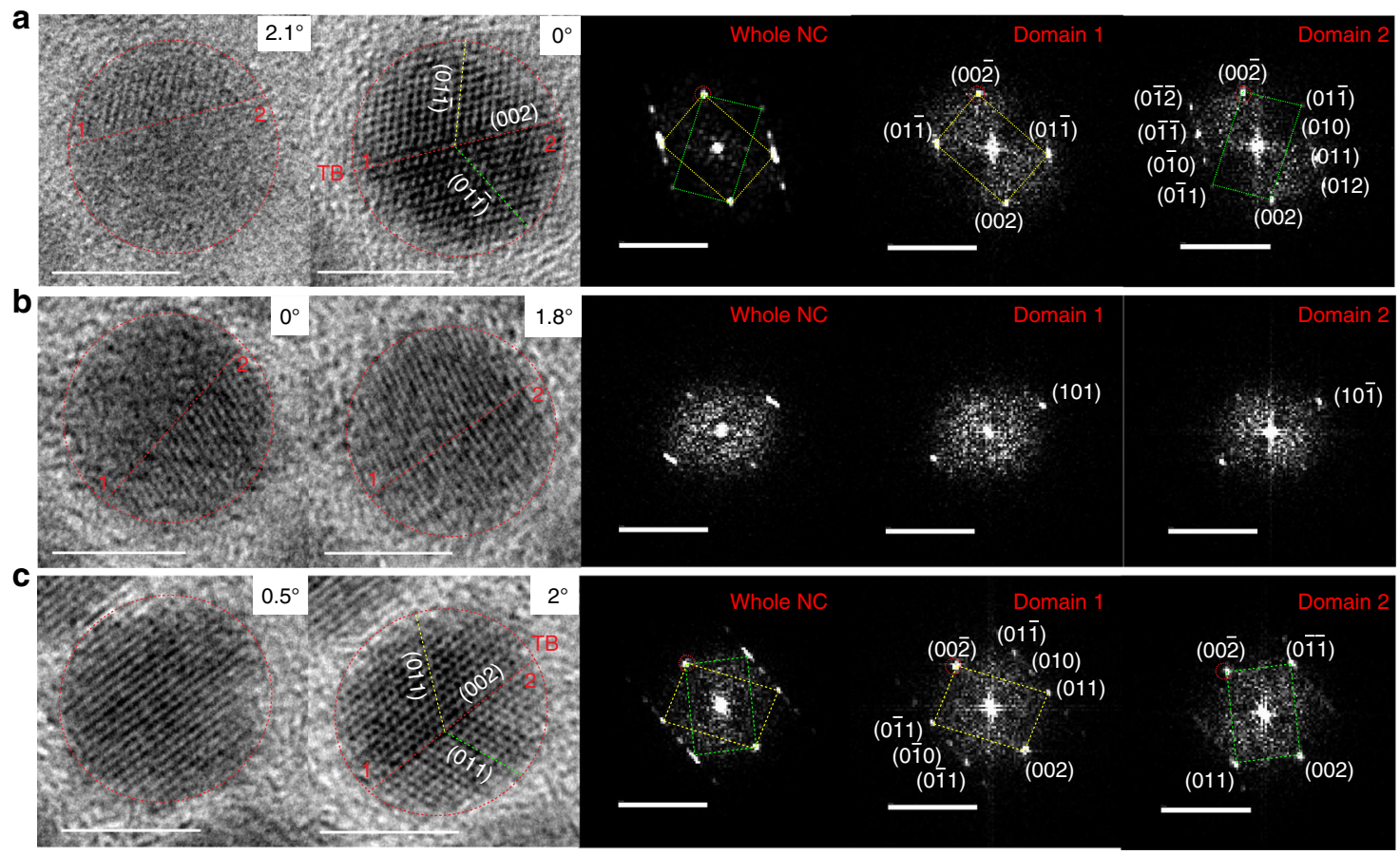

Fig. 3 Identification of twinning. Twinned domains in $\mathrm{Cu}_{1.93} \mathrm{~S} \mathrm{NCs} \mathrm{verified} \mathrm{by} \mathrm{tilt-dependent} \mathrm{HRTEM} \mathrm{imaging} \mathrm{of} \mathrm{(a-c)} \mathrm{three} \mathrm{representative} \mathrm{NCs.} \mathrm{From} \mathrm{left} \mathrm{to}$ right: image of NC without tilt, image of the same NC after a small tilt (about an axis located in the image plane oriented $\sim 25^{\circ}$ clockwise with respect to the vertical direction of the image plane), fast-Fourier transform (FFT) of the whole real-space image obtained under tilt, and select-area FFTs of the individual domains, labeled 1 and 2 in the real-space image. In the real-space images, the NC boundary is marked by a dotted red circle. The twin boundary (TB) is marked by a dotted red line and the reflection spot corresponding to the shared twin plane is marked by a dotted red circle in the FFTs. The crystallographic planes which have a mirror relationship across the twin boundary are marked by yellow (domain 1) and green (domain 2) dotted lines in the real-space image. Corresponding reciprocal lattice patterns for the two domains are indicated in the FFTs by parallelograms of the corresponding color. Several reciprocal lattice spots are assigned to specific planes of the high chalcocite phase and labeled by Miller indices. Scale bars in real-space images are $5 \mathrm{~nm}$ in length and those in FFTs are $5 \mathrm{~nm}^{-1}$

overlap of the reciprocal lattice spot patterns of the two domains ${ }^{26}$.

Figure $3 \mathrm{~b}$ and $\mathrm{c}$ present two other examples of such twinned domains within a NC. In the third example (Fig. 3c), the NC appears to be single-domain when imaged without tilt; but in the image acquired at a tilt of $1.8^{\circ}$, two domains with a twinning relationship are clearly observed. This example highlights that for some NCs, the zone-axis is perpendicular to the TB making it difficult to identify the twinned domains, unless the imaging plane is subject to a small tilt. As a result, the fraction of NCs reported in Fig. 2e to have multiple domains may be somewhat underestimated.

Crystallographic structures of $\mathrm{Cu}_{2-x} \mathrm{~S}$ NCs. Room temperature powder X-ray diffraction (PXRD) was employed to determine structures of the $\mathrm{Cu}_{2-x} \mathrm{~S}$ NCs of all four stoichiometries (Fig. 4). The composition of $\mathrm{Cu}_{1.97} \mathrm{~S}$ is intermediate between that of the fully stoichiometric $\left(\mathrm{Cu}_{32} \mathrm{~S}_{16}\right.$ or $\left.\mathrm{Cu}_{2} \mathrm{~S}\right)$ low chalcocite phase and the stable $\mathrm{Cu}$-deficient $\left(\mathrm{Cu}_{31} \mathrm{~S}_{16}\right.$ or $\left.\mathrm{Cu}_{1.9375} \mathrm{~S}\right)$ djurleite phase. The PXRD pattern of $\mathrm{Cu}_{1.97} \mathrm{~S}$ NCs is closely modeled by a simulated pattern of a 1:1 mixture of low chalcocite and djurleite phases (Fig. 4b) with a domain size of $6.3 \mathrm{~nm}$, which was determined on the basis of Debye-Scherer broadening of the $2 \theta \sim 37^{\circ}$ reflection (Fig. 4c). The domain size is close to the average NC diameter of $7.2 \mathrm{~nm}$ determined by TEM (Fig. 1c), which is consistent with the mostly single-domain nature of the $\mathrm{Cu}_{1.97} \mathrm{~S}$ NCs.

$\mathrm{Cu}_{1.93} \mathrm{~S}$ NCs have the stoichiometry of the djurleite phase ${ }^{14}$. The PXRD pattern of these NCs can be assigned to the djurleite phase $^{27}$, but the reflection peaks appear at slightly smaller $2 \theta$ (Fig. 4a), yielding closer agreement with the high-temperature phase, which is defined by a hexagonal arrangement of $\mathrm{S}^{2-}$, a mobile $\mathrm{Cu}^{+}$sub-lattice, and a $1.5 \%$ larger unit cell volume than the djurleite phase, which has an immobile $\mathrm{Cu}^{+}$sub-lattice ${ }^{28}$. The high temperature form of djurleite (which we refer to as high djurleite), is crystallographically indistinguishable from the high chalcocite phase despite the $\mathrm{Cu}$-deficiency of the former. Due to the mobile, disordered $\mathrm{Cu}^{+}$sub-lattice, the crystal arrangement is dominated by the $\mathrm{S}^{2-}$ sub-lattice.

Another key observation is the broadening of the PXRD peaks as the $\mathrm{Cu}$-deficiency level increases from $\mathrm{Cu}_{1.97} \mathrm{~S}$ to $\mathrm{Cu}_{1.93} \mathrm{~S}$ (Fig. 4a). In fact, in the $\mathrm{Cu}_{1.93} \mathrm{~S}$ NCs, the peaks at $2 \theta$ of $\sim 46^{\circ}$ and $\sim 48^{\circ}$ are fully overlapped. The larger peak broadening for the $\mathrm{Cu}_{1.93} \mathrm{~S} \mathrm{NCs}$ is indicative of smaller domains, as further verified by the domain size calculated from Debye-Scherrer broadening of the $2 \theta \sim 37^{\circ}$ peak (Fig. $4 \mathrm{c}$ ). The average domain size $(3.8 \mathrm{~nm})$ is appreciably smaller than the average NC diameter $(7.2 \mathrm{~nm})$, which is consistent with the multi-domain structure of the $\mathrm{Cu}_{1.93} \mathrm{~S}$ NCs resulting from twinning. The average domain size is found to decrease with an increase in the $\mathrm{Cu}$-deficiency level (Fig. 4c). This trend goes hand-in-hand with the observed increase in the prevalence of the multi-domain NCs with increasing $x$ (Fig. 2e).

Origin of twinning in Cu-deficient NCs. The Cu-deficient djurleite form has a monoclinic unit cell $\left(a_{\mathrm{dj}}=26.90 \AA, b_{\mathrm{dj}}=\right.$ $15.75 \AA$, $c_{\mathrm{dj}}=13.57 \AA$, $\beta_{\mathrm{dj}}=90.13^{\circ}$ ) which is nearly orthorhombic and has a special relationship between its lattice parameters: $a_{\mathrm{dj}}$ $\sim \sqrt{3} b_{\mathrm{dj}}{ }^{29}$. As a result, multiple monoclinic unit cells can fit into a higher-symmetry supercell of pseudohexagonal structure, as illustrated in Fig. 5b. The twinning of the monoclinic structure is 
a

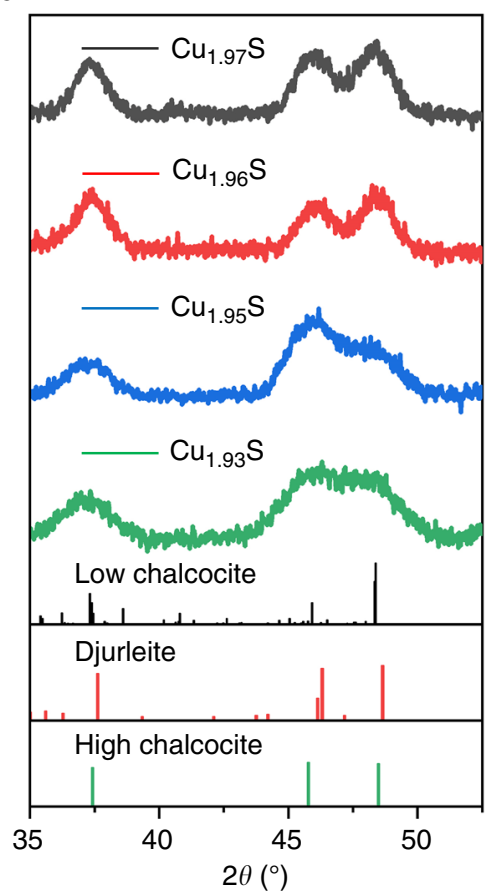

b

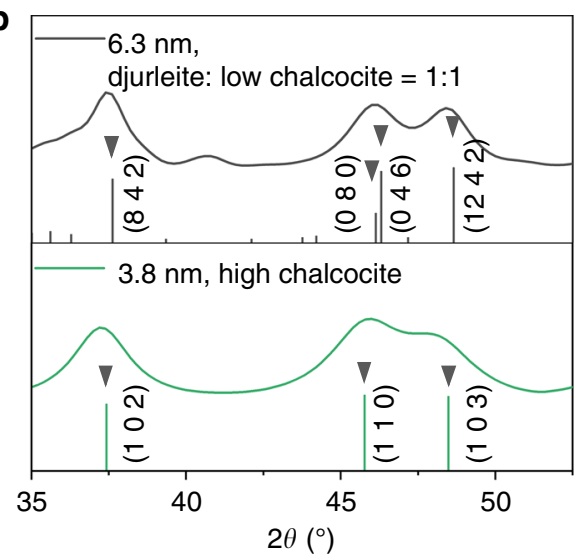

C

\begin{tabular}{cc} 
Stoichiometry & $\begin{array}{c}\text { Domain size } \\
(\mathrm{nm})\end{array}$ \\
\hline $\mathrm{Cu}_{1.97} \mathrm{~S}$ & 6.3 \\
\hline $\mathrm{Cu}_{1.96} \mathrm{~S}$ & 5.3 \\
\hline $\mathrm{Cu}_{1.95} \mathrm{~S}$ & 3.8 \\
\hline $\mathrm{Cu}_{1.93} \mathrm{~S}$ & 3.8 \\
\hline
\end{tabular}

Fig. 4 Sub-stoichiometry-dependent crystallographic structures of the NCs. a Experimental PXRD patterns of $\mathrm{Cu}_{2-x} \mathrm{~S} N C s$ for four levels of substoichiometry. Reference patterns are also shown for low chalcocite (JCPDS \# 33-0490), djurleite (JCPDS \# 23-0959) and high chalcocite (JCPDS \# 26-1116) by stick patterns. $\mathbf{b}$ Simulated PXRD patterns of $\mathrm{Cu}_{2-x} \mathrm{~S} \mathrm{NCs} \mathrm{in} \mathrm{a} \mathrm{1:1} \mathrm{mixture} \mathrm{of} \mathrm{djurleite:} \mathrm{low} \mathrm{chalcocite} \mathrm{phase} \mathrm{and} \mathrm{a} \mathrm{high} \mathrm{chalcocite} \mathrm{phase} \mathrm{with} \mathrm{key}$ peaks assigned to specific Miller planes. For the input parameters for each simulated pattern, refer to Supplementary Tables 1-3. Reference patterns are also shown for djurleite (black sticks) and high chalcocite (green sticks). c NC domain size determined from Debye-Scherrer broadening (see Supplementary Table 4) of the $2 \theta \sim 37^{\circ}$ reflection of the experimental PXRD pattern
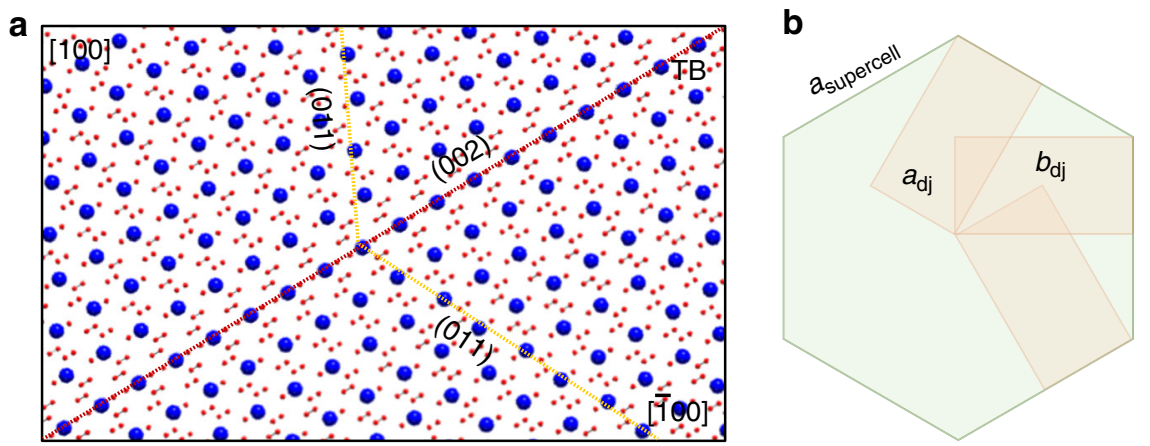

Fig. 5 Origin of twinning. a Schematic of twinning in a high chalcocite lattice ( $\mathrm{S}^{2-}$ shown in blue; $\mathrm{Cu}^{+}$in red). The twin boundary (TB) is denoted by the dotted red line and key crystallographic planes are indicated by dotted yellow lines. $\mathbf{b}$ Symmetry relationship of a unit cell of near-orthorhombic djurleite (camel tetragon) to its supercell (green hexagon) of pseudo-hexagonal symmetry ${ }^{41} \cdot a_{\mathrm{dj}}$ and $b_{\mathrm{dj}}$ are lattice constants of the djurleite unit cell, while $a_{\mathrm{supercell}}$ is the lattice constant of the supercell in the basal plane. The symmetry relationship is possible because $a_{\mathrm{dj}} \sim \sqrt{3} b_{\mathrm{dj}}$

favored as a result of this symmetry relationship. At the high temperature at which the synthesis is performed, the NCs are formed with a high-temperature hexagonal arrangement of $\mathrm{S}^{2-}$. Cooling imposes a transition from this higher-symmetry hexagonal form to the lower symmetry monoclinic form. The lost symmetry element instead becomes a twin law: the monoclinic lattice formed is non-merohedrally twinned such that it adopts a hexagonal supercell ${ }^{26}$. This explains why NCs synthesized with the djurleite composition undergo twinning (Fig. 5a).

On the other hand, the stoichiometric low chalcocite unit cell $\left(a_{\mathrm{lc}}=15.25 \AA, b_{\mathrm{lc}}=11.88 \AA, c_{\mathrm{lc}}=13.49 \AA, \beta_{\mathrm{lc}}=116.35^{\circ}\right)$ does not exhibit such a symmetry relationship ${ }^{29}$. As a result, NCs closer to low chalcocite in composition, do not favor twinning. The propensity of twinning increases as we go from a composition of $\mathrm{Cu}_{1.97} \mathrm{~S}$ to $\mathrm{Cu}_{1.93} \mathrm{~S}$, i.e., as the djurleite composition is approached.

Influence of twinning on phase transition characteristics. The twinned structure of the $\mathrm{Cu}_{2-x} \mathrm{~S}$ NCs influences their properties, specifically their phase and phase transition characteristics, as revealed by differential scanning calorimetry (DSC) measurements. Figure 6a shows the DSC thermograms of $\mathrm{Cu}_{2-x} \mathrm{~S} \mathrm{NCs}$ of the four different $\mathrm{Cu}$-deficiency levels. In each case, the endothermic peak observed in the heating sub-cycle of the thermogram signifies a phase transition from the low-temperature phase to the high-temperature superionic phase of $\mathrm{Cu}_{2-x} \mathrm{~S}$. The peak 

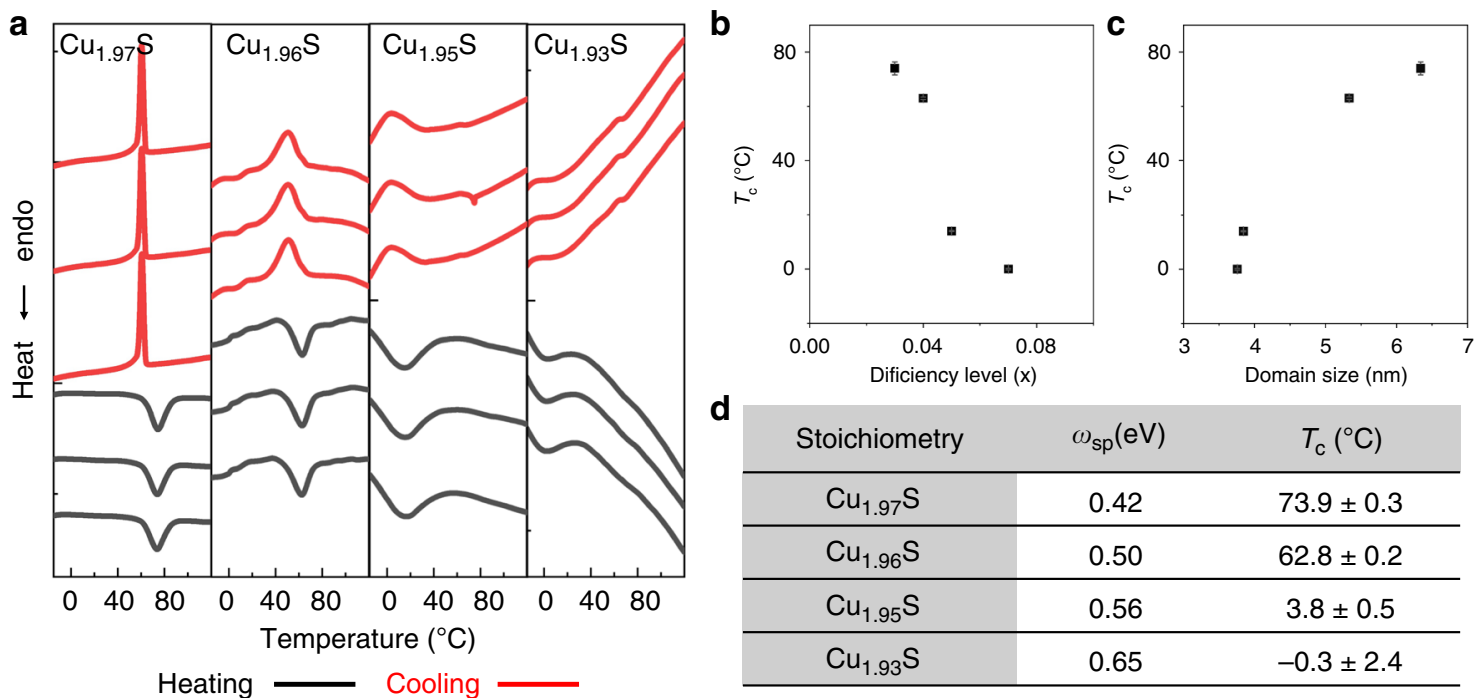

\begin{tabular}{ccc} 
d & $\omega_{\mathrm{sp}}(\mathrm{eV})$ & $T_{\mathrm{c}}\left({ }^{\circ} \mathrm{C}\right)$ \\
\hline $\mathrm{Cu}_{1.97} \mathrm{~S}$ & 0.42 & $73.9 \pm 0.3$ \\
\hline $\mathrm{Cu}_{1.96} \mathrm{~S}$ & 0.50 & $62.8 \pm 0.2$ \\
\hline $\mathrm{Cu}_{1.95} \mathrm{~S}$ & 0.56 & $3.8 \pm 0.5$ \\
\hline $\mathrm{Cu}_{1.93} \mathrm{~S}$ & 0.65 & $-0.3 \pm 2.4$ \\
\hline
\end{tabular}

Fig. 6 Effect of twinning on phase transition characteristics. a DSC thermograms of ca. $7 \mathrm{~nm}$ diameter $\mathrm{Cu}_{2-x} \mathrm{~S}$ NCs of four levels of sub-stoichiometry. In each case, thermograms from three consecutive heating-cooling cycles performed on the same sample of NCs are shown, from which the reproducibility of the phase-transition peaks (dips) is evident. The thermograms are vertically offset for stacking. The peak temperature of the phase-transition in the heating sub-cycle was averaged across the three cycles to yield $T_{\mathrm{c}}$ and the standard deviation in $T_{\mathrm{c}} . T_{\mathrm{c}}$ plotted as a function of $\mathbf{b}$ the $\mathrm{Cu}$-deficiency level, $x$, and $\mathbf{c}$ the domain size determined from PXRD. Error bars representing the standard deviation are shown for each data-point; but they are not resolvable in cases where the standard deviation is small. $\mathbf{d}$ Table of characteristics of the $\mathrm{Cu}_{2-x} \mathrm{~S} \mathrm{NCs}$ as a function of the deficiency level. Values of $\omega_{\mathrm{sp}}$ correspond the LSPR peak maxima from Fig. 1a. The tabulated $T_{\mathrm{c}}$ values represent the average \pm standard deviation, also plotted in $\mathbf{b}$, $\mathbf{c}$. The analysis described here was conducted for several batches of NCs and the variability in $\omega_{\mathrm{sp}}$, stoichiometry, and $T_{\mathrm{c}}$ was determined (see Supplementary Table 5)

maximum is defined as the phase transition temperature $\left(T_{\mathrm{c}}\right)$. Upon cooling, the phase transition is reversed as signified by the exothermic peak. The reproducibility of the transition peaks over multiple heating-cooling cycles signify the reversibility of the phase transition and the thermostability of the NCs over the course of the phase cycling.

For $\mathrm{Cu}_{1.97} \mathrm{~S} \mathrm{NCs}$, the $T_{\mathrm{c}}$ is observed to be $74^{\circ} \mathrm{C}$, whereas in the bulk, the temperature for such a transition is $\sim 104^{\circ} \mathrm{C}$ (for chalcocite) and $97{ }^{\circ} \mathrm{C}$ (for djurleite) $)^{14}$. The lower $T_{\mathrm{c}}$ for the NCs is due to the nanoscale size effect, which is known to result in a depression in phase transition temperatures ${ }^{30-32}$. For the $\mathrm{Cu}_{1.93} \mathrm{~S}$ NCs, which possess a twinned multi-domain structure (Fig. 2e), the $T_{\mathrm{c}}$ is $0^{\circ} \mathrm{C}$, which is $74^{\circ} \mathrm{C}$ lower than that of the single-domain $\mathrm{Cu}_{1.97} \mathrm{~S}$ NCs. In fact, there is systematic decrease in the $T_{\mathrm{c}}$ as $x$ increases (Fig. 6b-d) and the average domain size decreases (Fig. 6c) due to the increased prevalence of twinned NCs. With increasing $x$, the phase transition peak also becomes broader, which is likely an outcome of heterogeneity in the domain structure and/or domain size across NCs. Thus, twinning results in a marked depression in the phase transition temperature of $\mathrm{Cu}_{2-x} \mathrm{~S}$. What is most noteworthy is that the $\mathrm{Cu}_{1.93} \mathrm{~S}$ NCs are in a superionic phase at room temperature. This is also why the $\mathrm{Cu}_{1.93} \mathrm{~S}$ NCs are found from room-temperature PXRD to be in the high-djurleite phase (Fig. 4a, b).

It was necessary to examine if the depression in the $T_{\mathrm{c}}$ in $\mathrm{Cu}_{1.93} \mathrm{~S}$ NCs is not simply the result of $\mathrm{Cu}$ deficiencies and is definitely an outcome of their twinned structure. $\mathrm{Cu}$ deficiencies in the $\mathrm{Cu}_{2} \mathrm{~S}$ lattice can result in lattice compression. Compressive lattice strain has been demonstrated to aid the stabilization of superionic phases of selenides at lower temperatures than in the unstrained lattice 33,34 . A control study was performed with NCs with a $\mathrm{Cu}$-deficient $\mathrm{Cu}_{1.93} \mathrm{~S}$ composition but no twinned domains. In this study, $\mathrm{Cu}_{1.97} \mathrm{~S} \mathrm{NCs}$ synthesized with no air exposure, were subject to post-synthetic air-oxidation to form more $\mathrm{Cu}$-deficient $\mathrm{Cu}_{1.93} \mathrm{~S}$ NCs. The resulting $\mathrm{Cu}_{1.93} \mathrm{~S}$ NCs have an average diameter of $6.2 \mathrm{~nm}$ and a single-domain structure similar to the assynthesized $\mathrm{Cu}_{1.97} \mathrm{~S}$ NCs (Fig. 7a-d and Supplementary Fig. 4).
The average domain size is also unchanged upon post-synthetic oxidation, as manifested by the width of the PXRD peak at $2 \theta$ $\sim 37^{\circ}$ (Fig. $7 \mathrm{e}$ ). In other words, post-synthetic oxidation did not result in twinning or multi-domain formation, unlike in-situ oxidation accomplished during hot-injection synthesis. Roomtemperature PXRD shows that the $\mathrm{Cu}_{1.93} \mathrm{~S}$ NCs are in the djurleite phase, and not the high-temperature superionic form (Fig. 7e). DSC characterization (Fig. 8) shows that as-synthesized $\mathrm{Cu}_{1.97} \mathrm{~S} \mathrm{NCs}$ and $\mathrm{Cu}_{1.93} \mathrm{~S}$ NCs formed by post-synthetic oxidation have a similar $T_{c}$ of $75^{\circ} \mathrm{C}$. These results indicate that a $\mathrm{Cu}-$ deficient composition alone, without twinning, does not lead to the $T_{\mathrm{c}}$ depression observed. Rather, twinning is responsible for the dramatic $T_{\mathrm{c}}$ depression and the room-temperature stabilization of the superionic phase in the $\mathrm{Cu}_{1.93} \mathrm{~S}$ NCs synthesized by insitu oxidation.

Mechanistic origin of twinning-induced $T_{c}$ depression. The formation of smaller domains and additional domain boundaries within a NC by twinning is the likely cause of the substantial $T_{\mathrm{c}}$ depression. Such an effect of smaller domains is best demonstrated by a study of $\mathrm{Cu}_{2-x} \mathrm{~S}$ NCs of a smaller diameter (Fig. 9a-c and Supplementary Fig. 5). NCs of ca. $7 \mathrm{~nm}$ diameter synthesized without air-injection show a $T_{c}$, on average, of $75^{\circ} \mathrm{C}$ (Supplementary Table 5); whereas NCs of a smaller diameter of ca. $3 \mathrm{~nm}$ synthesized without air-injection show a significantly lower $T_{\mathrm{c}}$ of $24^{\circ} \mathrm{C}$ (Fig. 9d).

Previously, we had found that in small cuprous selenide nanoclusters, the superionic phase is observed at much lower temperatures than in the bulk solid ${ }^{34}$. While phenomenologically similar, the depression in the $T_{\mathrm{c}}$ seen here for the twinned $\mathrm{Cu}_{2-x} \mathrm{~S}$ NCs is purported to be different in mechanistic origin. In cuprous selenide, the superionic phase has a compressed lattice as compared to the ordered phase ${ }^{35,36}$. As a consequence, compressive strain prevalent in small nanocrystals results in the stabilization of the superionic phas $\mathrm{e}^{33}$. In contrast, in cuprous sulfide, the superionic high chalcocite phase has nearly 

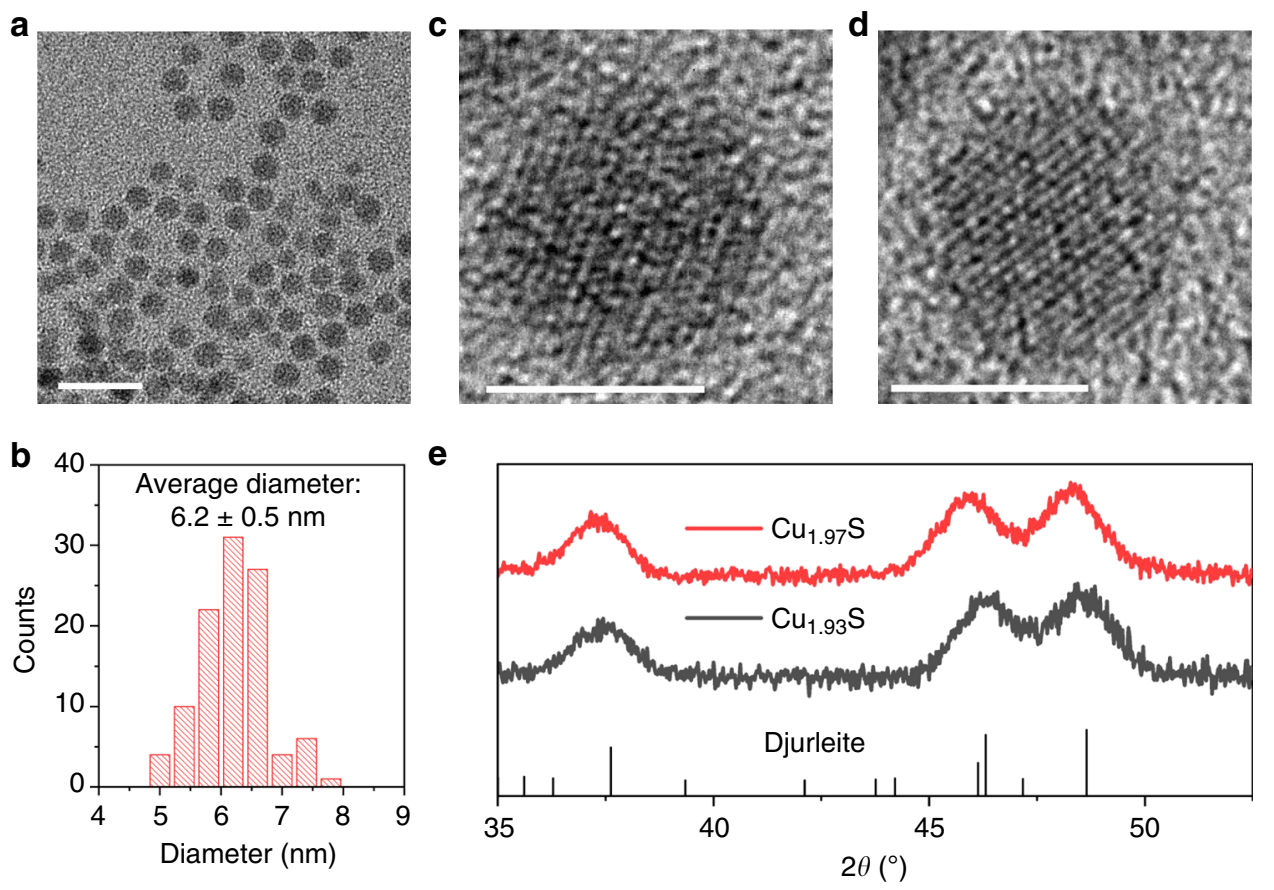

Fig. 7 Structural characteristics of $\mathrm{Cu}_{1.93} \mathrm{~S} \mathrm{NCs}$ prepared by post-synthetic air oxidation. a Wide-field TEM image (scale bar $\left.=20 \mathrm{~nm}\right)$ of $\mathrm{Cu}_{1.93} \mathrm{~S} \mathrm{NCs}$ synthesized by the hot-injection method and $\mathbf{b}$ histogram showing NC diameter distribution determined by Image J analysis of the TEM image in $\mathbf{a}$. The average diameter of the NCs is determined to be $6.2 \mathrm{~nm}$ with a standard deviation of $0.5 \mathrm{~nm}$. HRTEM image (scale bar $=5 \mathrm{~nm}$ ) of a representative NC of $\mathbf{c}$ $\mathrm{Cu}_{1.97} \mathrm{~S}$ and $\mathbf{d} \mathrm{Cu}_{1.93} \mathrm{~S}$ obtained from $\mathrm{Cu}_{1.97} \mathrm{~S}$ by post-synthetic air exposure. experimental PXRD patterns of $\mathrm{Cu}_{1.97} \mathrm{~S} \mathrm{NCs}$ and $\mathrm{Cu}_{1.93} \mathrm{~S} \mathrm{NCs} \mathrm{prepared} \mathrm{by} \mathrm{air}$ oxidation of $\mathrm{Cu}_{1.97} \mathrm{~S} \mathrm{NCs}$ for $24 \mathrm{~h}$. The reference pattern of djurleite phase (JCPDS \# 23-0959) is shown by the stick plot. The sub-stoichiometry was estimated from the LSPR peak energy for the corresponding NCs $\left(0.42 \mathrm{eV}: \mathrm{Cu}_{1.97} \mathrm{~S}\right.$ and $\left.0.65 \mathrm{eV}: \mathrm{Cu}_{1.93} \mathrm{~S}\right)$
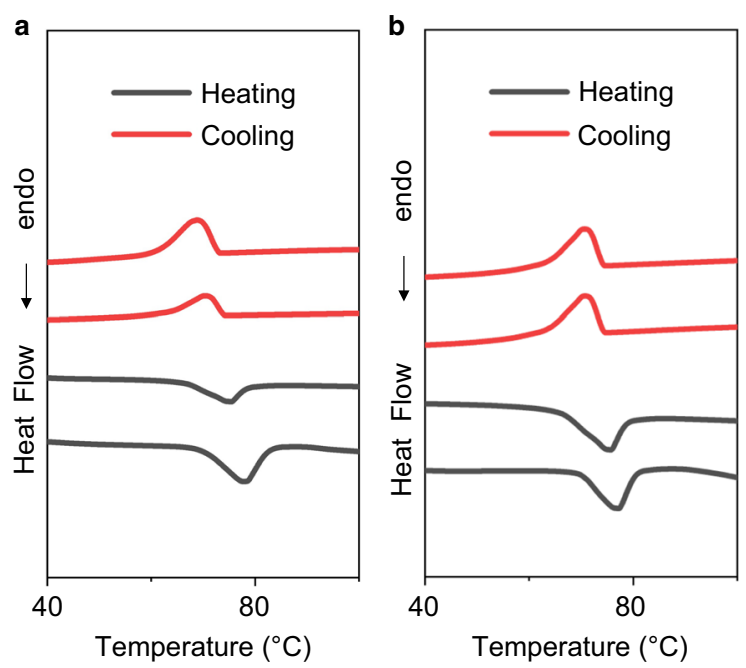

Fig. 8 Phase-transition characteristics of $\mathrm{Cu}_{1.93} \mathrm{~S}$ NCs prepared by postsynthetic air oxidation. DSC thermograms of $\mathbf{a} \mathrm{Cu}_{1.97} \mathrm{~S} \mathrm{NCs} \mathrm{synthesized} \mathrm{by}$ hot-injection and $\mathbf{b} \mathrm{Cu}_{1.93} \mathrm{~S} \mathrm{NCs}$ obtained from post-synthetic air exposure of $\mathrm{Cu}_{1.97} \mathrm{~S} \mathrm{NCs}$ for $12 \mathrm{~h}$. In each case, thermograms from two heating-cooling cycles performed on the same sample of NCs are shown, from which the reproducibility of the phase-transition peaks (dips) is evident. The thermograms are vertically offset for stacking. The peak temperature of the phase-transition in the heating sub-cycle was averaged across the two cycles to yield $T_{\mathrm{c}}$. Note this study was performed on a different batch of NCs compared to the one in Fig. 7

the same lattice volume as that of the low chalcocite phase and a marginally larger lattice volume than the djurleite phase ${ }^{37}$. Compressive strain is, therefore, not likely to cause the $T_{\mathrm{c}}$ depression seen here.
Similar to the effect of a decreased NC size ${ }^{31}$, twinning results in an increase in the interfacial energy ${ }^{38}$, albeit without a change in the overall volume of the NC. This interfacial energy contributed by twin boundaries can lead to a depression in the $\mathrm{Cu}^{+}$sub-lattice melting temperature (i.e., the $T_{\mathrm{c}}$ ) as explained below:

$$
T_{\mathrm{c}}=\frac{\Delta H}{\Delta S}
$$

where $\Delta H$ and $\Delta S$, respectively, represent the specific enthalpy and entropy change involved in the transition from the lowtemperature phase to the superionic high-temperature phase. For the bulk solid:

$$
T_{\mathrm{c}}^{\text {bulk }}=\frac{\Delta H^{\text {bulk }}}{\Delta S}
$$

But for a NC, the specific enthalpy of the low-temperature phase has an additional contribution from the non-negligible interfacial energy of the NC surface, therefore:

$$
\Delta H=\Delta H^{\text {bulk }}-\frac{\zeta_{s} \cdot A_{s}}{\rho \cdot V}
$$

where $\zeta_{\mathrm{s}}$ is the surface energy (per unit area), $\rho$ is the density, and $A_{\mathrm{s}}$ and $V$ are, respectively, the surface area and volume of the NC. Furthermore, if the NC has internal twin boundaries, there is an addition interfacial energy contribution, therefore:

$$
\Delta H=\Delta H^{\text {bulk }}-\frac{\zeta_{s} \cdot A_{s}}{\rho \cdot V}-\frac{\zeta_{\mathrm{TB}} \cdot A_{\mathrm{TB}}}{\rho \cdot V}
$$

where $\zeta_{\text {Тв }}$ is the interfacial energy of twin boundaries (per unit area) and $A_{\mathrm{TB}}$ is the net area of the twin boundaries. Thus, for a 

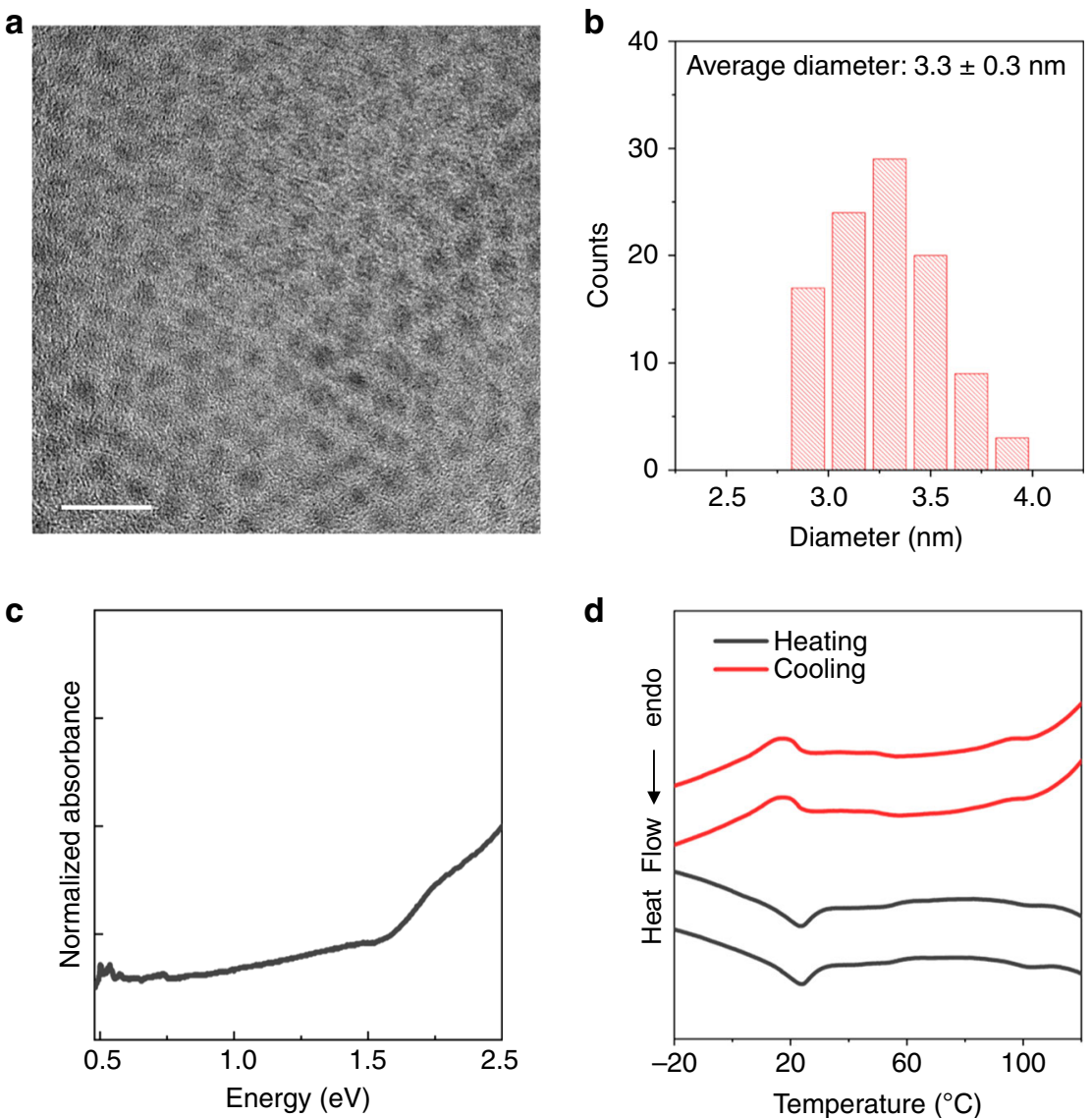

Fig. 9 Characteristics of $\mathrm{Cu}_{2-x} \mathrm{~S} \mathrm{NCs}$ of a smaller size. a Representative TEM image (scale bar $=10 \mathrm{~nm}$ ) of $\mathrm{Cu}_{2-x} \mathrm{~S}$ NCs of a smaller diameter prepared with no air-injection and $\mathbf{b}$ histogram showing the NC diameter distribution determined by ImageJ analysis of the TEM image. The average diameter of the NCs is determined to be $3.3 \mathrm{~nm}$ with a standard deviation of $0.3 \mathrm{~nm}$. c Vis-NIR extinction spectrum (normalized to 1 at $2 \mathrm{eV}$ ) of the $\mathrm{Cu}_{2-x} \mathrm{~S} \mathrm{NCs}$ of $3.3 \mathrm{~nm}$ average diameter. The NCs synthesized with no air-injection are expected to have a stoichiometry of $\mathrm{Cu}_{1.97} \mathrm{~S}$ analogous to the case of ca. $7 \mathrm{~nm}$ diameter $\mathrm{NCs}$, however the LSPR absorption of these smaller NCs was too weak to assign an $\omega_{\mathrm{sp}}$. It is possible the NCs are nearly $\mathrm{Cu}_{2} \mathrm{~S}$ in stoichiometry. $\mathbf{d} \mathrm{DSC}$ thermograms of the these NCs. Thermograms from two heating-cooling cycles performed on the same sample of NCs are shown, from which the reproducibility of the phase-transition peaks (dips) is evident. The peak temperature of the phase-transition in the heating sub-cycle was averaged over the two cycles to yield a $T_{\mathrm{c}}$ of $24^{\circ} \mathrm{C}$ with a standard deviation of $0.3^{\circ} \mathrm{C}$

NC with twin boundaries:

$$
T_{\mathrm{c}}^{\mathrm{TNC}}=\frac{\Delta H^{\mathrm{bulk}}-\frac{\zeta_{\mathrm{s}} \cdot A_{\mathrm{s}}}{\rho \cdot V}-\frac{\zeta_{\mathrm{TB}} \cdot A_{\mathrm{TB}}}{\rho \cdot V}}{\Delta S}=T_{\mathrm{c}}^{\mathrm{bulk}}\left(1-\frac{\zeta_{\mathrm{s}} \cdot A_{\mathrm{s}}}{\rho \cdot V}-\frac{\zeta_{\mathrm{TB}} \cdot A_{\mathrm{TB}}}{\rho \cdot V}\right)
$$

which implies that the $T_{\mathrm{c}}$ of a NC with twin boundaries, (i.e., $T_{\mathrm{c}}^{\mathrm{TNC}}$ ) would be lower than that of the bulk crystal due to the combined effect of the NC surface and the twin boundaries. The relative depression in the $T_{\mathrm{c}}$ for a twinned $\mathrm{NC}$ with respect to the bulk value (i.e., $T_{\mathrm{c}}^{\mathrm{bulk}}$ ) is given as:

$$
\frac{\left(T_{\mathrm{c}}^{\text {bulk }}-T_{\mathrm{c}}^{\mathrm{TNC}}\right)}{T_{\mathrm{c}}^{\text {bulk }}}=\left(\frac{\zeta_{\mathrm{s}} \cdot A_{\mathrm{s}}}{\rho \cdot V \cdot \Delta H^{\text {bulk }}}+\frac{\zeta_{\mathrm{TB}} \cdot A_{\mathrm{TB}}}{\rho \cdot V \cdot \Delta H^{\text {bulk }}}\right)
$$

The first term on the right-hand side represents the depression caused by the nanoscale size. The smaller the NC size, the higher the surface area-to-volume ratio $\left(A_{\mathrm{s}} / V\right)$ and the larger is this contribution. The second term on the right-hand side represents the additional depression caused by the presence of twin boundaries. Higher the density of twin boundaries $\left(A_{\mathrm{TB}} / V\right)$, greater is this depression. This simple model thus explains the reduction in the $T_{\mathrm{c}}$ caused by the presence of twinning.

In summary, we have developed a method for the preparation of $\mathrm{Cu}_{2-x} \mathrm{~S}$ NCs with a tunable internal domain structure. The method employs in situ oxidation during hot-injection synthesis for the growth of $\mathrm{NCs}$ with a defined $\mathrm{Cu}$-deficiency level. By tuning of the $\mathrm{Cu}$-deficiency level, NCs were synthesized with structures ranging from single-domain to multi-domain. The formation of multiple domains within $\mathrm{Cu}$-deficient NCs occurs via crystal-twinning. It is found that the internal structure influences the ionic structure and properties of the NCs. NCs of ca. $7 \mathrm{~nm}$ diameter with twinned domains are stable in the superionic phase at temperatures as low as $0{ }^{\circ} \mathrm{C}$; whereas for single-domain NCs, the transition to the superionic phase occurs only above $74{ }^{\circ} \mathrm{C}$. The contribution of twin boundaries to the interfacial energy of the NCs is thought to cause the marked depression of the transition temperature. Not only do these findings open up the use of earth-abundant $\mathrm{Cu}_{2-x} \mathrm{~S}$ as a roomtemperature superionic conductor, but they also highlight, more generally, the utility of internal structural engineering for nanoscale materials design. The nanostructures developed here provide opportunities for investigating the influence of twinned interfaces on electronic and ionic transport ${ }^{39}$.

\section{Methods}

Chemicals. Copper (II) acetylacetonate (Cu(acac) $)_{2}$, Alfa Aesar, 98\%), 1-octadecane (ODE, Sigma-Aldrich, 90\%), 1-dodecanethiol (DDT, Sigma-Aldrich, > 98\%), acetone (Fisher, 99.5\%), hexane (Sigma-Aldrich, 98.5\%), and tetrachloroethylene (Alfa Aesar, 99\%). 
Synthesis of $\mathbf{C u}_{2-x} \mathbf{S} \mathbf{N C s}$ with in situ oxidation. A common synthesis procedure known from literature was modified to incorporate in situ oxidation ${ }^{21}$. In a typical synthesis, $0.1 \mathrm{~g}$ of $\mathrm{Cu}(\mathrm{acac})_{2}$ and $0.3 \mathrm{~mL}$ of DDT were mixed in a $25 \mathrm{~mL}$ three-neck, round-bottom glass flask, which was followed by the addition of $2.8 \mathrm{~mL}$ of ODE. The flask was then connected to a Schlenk line and subject to a vacuum for $0.5 \mathrm{~h}$, after which the flask was brought to an Ar environment. To achieve a controlled degree of in-situ oxidation, a specific volume of air $(0 \mathrm{~mL}, 0.01 \mathrm{~mL}, 0.1 \mathrm{~mL}$, and $1.0 \mathrm{~mL}$ ) was injected into the flask. Air was injected using a $1 \mathrm{~mL}$ syringe. For injection of 0.1 and $1 \mathrm{~mL}$ volumes, air was injected into the three-neck flask through a rubber septum capping one of the side-necks. For injection of a $0.01 \mathrm{~mL}$ volume, a gas mixture of $\mathrm{Ar}$ and air in a volumetric ratio of 9:1 was prepared in a glass vial. Then, $0.1 \mathrm{~mL}$ of this gas mixture was injected into the reaction flask using a $1 \mathrm{~mL}$ syringe. The solution was heated to $200^{\circ} \mathrm{Cunder}$ stirring and allowed to react for $1.5 \mathrm{~h}$. The reaction was stopped by removing the heater and allowing the flask to cool down to room temperature. The $\mathrm{Cu}_{2-x} \mathrm{~S} \mathrm{NC}$ colloid resulting from the reaction was washed with acetone and hexane and NCs were isolated by centrifugation $(10,500 \mathrm{rpm}$ for $10 \mathrm{~min})$ for three times. The purified NCs were dispersed in $5.0 \mathrm{~mL}$ of hexane for further characterization. All post-synthetic processing of NCs and sample preparation was performed under inert gas (Ar or $\mathrm{N}_{2}$ ). The presence of air in the high-temperature synthesis resulted in the formation of NCs of a Cu-deficient composition by the oxidative removal of $\mathrm{Cu}$ from the $\mathrm{Cu}_{2} \mathrm{~S}$ lattice.

The sub-stoichiometry $(x)$ was determined from the peak energy of the LSPR band $\left(\omega_{\mathrm{sp}}\right)$ in the visible-near-infrared (vis-NIR) extinction spectrum measured for the NCs. Vis-NIR extinction spectra of the NCs were collected in a $1 \mathrm{~cm}$ pathlength NIR-transparent cuvette using a Shimadzu UV-3600 UV-vis-NIR spectrophotometer. The NCs were dispersed in tetrachloroethylene because this solvent has high transmission across the NIR region of interest. Typically, $0.2 \mathrm{~mL}$ of the as-synthesized NC colloid was mixed with $0.4 \mathrm{~mL}$ of acetone and centrifuged at $8000 \mathrm{rpm}$ for $10 \mathrm{~min}$. The precipitated NCs were redispersed in $2 \mathrm{~mL}$ of tetrachloroethylene for measurement of the vis-NIR extinction spectrum. From the $\omega_{\mathrm{sp}}$, the sub-stoichiometry was found to be dictated by the volume of air introduced: $\left(0 \mathrm{~mL}: \mathrm{Cu}_{1.97} \mathrm{~S}: 0.01 \mathrm{~mL}: \mathrm{Cu}_{1.96} \mathrm{~S}, 0.1 \mathrm{~mL}: \mathrm{Cu}_{1.95} \mathrm{~S}\right.$, and $\left.1 \mathrm{~mL}: \mathrm{Cu}_{1.93} \mathrm{~S}\right)$. Further increase in the volume of air introduced or even conducting the hotinjection synthesis fully exposed to air did not yield NCs appreciably more substochiometric than the $\mathrm{Cu}_{1.93} \mathrm{~S}$ composition, which likely reflects the fact that the djurleite form with a composition in the vicinity of $\mathrm{Cu}_{1.93} \mathrm{~S}$ represents a thermodynamically stable phase of $\mathrm{Cu}_{2-x} \mathrm{~S}$ in air ${ }^{40}$.

The size of the NCs was tuned by adjusting the molar ratio of $\mathrm{Cu}(\mathrm{acac})_{2}$ to DDT. The reagent amounts listed above resulted in NCs of ca. $7 \mathrm{~nm}$ average diameter. NCs of a smaller ca. $3 \mathrm{~nm}$ average diameter were obtained by decreasing the reaction time to $45 \mathrm{~min}$ while keeping all other conditions the same. An alternative method for obtaining ca. $3 \mathrm{~nm}$ diameter NCs is to conduct the synthesis using $0.15 \mathrm{~g}$ of $\mathrm{Cu}(\mathrm{acac})_{2}, 0.1 \mathrm{~mL}$ of DDT, and $3.8 \mathrm{~mL}$ of ODE while keeping the reaction time at $1.5 \mathrm{~h}$.

Post-synthetic oxidation of $\mathbf{C u}_{\mathbf{2}-\mathbf{x}} \mathbf{S} \mathbf{~ N C s}$. The synthesized NC colloid was diluted a few-fold with hexane and exposed to ambient air at room temperature under stirring. Typically, vis-NIR extinction spectra of the colloid were collected at periodic intervals $(0.5,2,12$, and $24 \mathrm{~h})$ to determine the $\mathrm{Cu}$-deficiency resulting from the air oxidation. From the LSPR peak energy, the NCs appear to reach a substoichiometry of $\mathrm{Cu}_{1.93} \mathrm{~S}$ after $12 \mathrm{~h}$ of air oxidation; NCs subject to air oxidation for 12 or more hours were assigned a stoichiometry of $\mathrm{Cu}_{1.93} \mathrm{~S}$.

Transmission electron microscopy. TEM images of the NCs were collected on a JEOL $2010 \mathrm{~F}$ instrument operating at $200 \mathrm{kV}$. Unless noted otherwise, samples for TEM were prepared by drop-casting tens of microliters of the NC colloid onto a carbon-coated Formvar film on a 200-mesh Cu grid (Ted Pella, 01800-F). Images were analyzed for NC size determination using the software, Nano Measurer. Crystallographic analysis of TEM images was performed using Digital Micrograph and ImageJ. NC boundaries and internal domains were identified manually in ImageJ.

Differential scanning calorimetry. $\mathrm{Cu}_{2-x} \mathrm{~S}$ NCs of different size, $\mathrm{Cu}$-deficiency level, and method of oxidation were characterized by DSC performed on a DSC Q20 V24.10 Build 122 or a TA Discovery 2500 instrument. For sample preparation, the NCs were isolated by subjecting the purified colloid to a non-solvent followed by centrifugation at $8000 \mathrm{rpm}$ for $10 \mathrm{~min}$. The precipitate was dried by application of vacuum. The resulting dried powder was transferred and compressed into a zero-T DSC aluminum pan. Thermograms were measured at a scan rate of $10^{\circ} \mathrm{C} /$ $\mathrm{min}$. Prior to the measurement, the sample was subject to a heating pre-cycle from -40 to $160^{\circ} \mathrm{Cfor}$ desorbing any remaining ligands from the NC surfaces, which may otherwise contribute to complicating features in the thermogram. Multiple successive heating-cooling cycles were performed for testing the reproducibility of the measured thermogram, the reversibility of the phase transition, and the stability of the NCs over the course of the phase cycling.

Powder X-ray diffraction. PXRD patterns of the NCs were collected on a Rigaku Miniflex 600 powder X-ray diffractometer operated at full power $(40 \mathrm{kV}, 15 \mathrm{~mA})$ with $\mathrm{Cu} K_{\alpha}$ radiation of a wavelength of $1.54 \AA$. Patterns were collected in reflection mode in the $2 \theta$ range of typically $20-80^{\circ}$ using a step size of $0.02^{\circ}$ with scans running for $\sim 2 \mathrm{~h}$. Typically, NCs were isolated from $500 \mu \mathrm{L}$ of the colloid by centrifugation. The pellet was dispersed in $50 \mu \mathrm{L}$ of hexane. The resulting colloid was drop-cast onto a zero-background quartz sample holder. Patterns were subject to manual baseline subtraction performed in Origin and appropriately scaled and vertically offset for presentation.

PXRD patterns were simulated using the PowderCell program, which performs a structure factor calculation using lattice parameters and atomic positions as input parameters. The input parameters for each simulated pattern are provided in Supplementary Tables 1-3. All simulated patterns include Debye-Scherrer broadening corresponding to a domain size estimated from experimental PXRD patterns (Supplementary Table 4). Simulated patterns were subject to manual baseline subtraction and were appropriately scaled and vertically offset for presentation.

\section{Data availability}

All raw images and source data are available from the authors upon reasonable request.

Received: 16 February 2019 Accepted: 26 June 2019

Published online: 23 July 2019

\section{References}

1. Spencer, L. J. Crystallography. in Encyclopadia Britannica 11th ed. (ed. Chisholm, H.) 569-591 (Cambridge University Press, Cambridge, U.K., 1911).

2. Huang, Q. et al. Nanotwinned diamond with unprecedented hardness and stability. Nature 510, 250-253 (2014).

3. Tian, Y. et al. Ultrahard nanotwinned cubic boron nitride. Nature 493, 385-388 (2013).

4. Davidson, F. M., Lee, D. C., Fanfair, D. D. \& Korgel, B. A. Lamellar twinning in semiconductor nanowires. J. Phys. Chem. C. 111, 2929-2935 (2007).

5. Carbone, L. et al. Multiple wurtzite twinning in CdTe nanocrystals induced by methylphosphonic acid. J. Am. Chem. Soc. 128, 748-755 (2006).

6. $\mathrm{Lu}, \mathrm{K}$. Stabilizing nanostructures in metals using grain and twin boundary architectures. Nat. Rev. Mater. 1, 16019 (2016).

7. Yang, H. et al. Plasmonic twinned silver nanoparticles with molecular precision. Nat. Commun. 7, 12809 (2016).

8. Tang, Y. \& Ouyang, M. Tailoring properties and functionalities of metal nanoparticles through crystallinity engineering. Nat. Mater. 6, 754-759 (2007).

9. Algra, R. E. et al. Twinning superlattices in indium phosphide nanowires. Nature 456, 369-372 (2008).

10. Bao, J. et al. Optical properties of rotationally twinned InP nanowire heterostructures. Nano Lett. 8, 836-841 (2008).

11. Wang, H., Zhou, S., Gilroy, K. D., Cai, Z. \& Xia, Y. Icosahedral nanocrystals of noble metals: synthesis and applications. Nano Today 15, 121-144 (2017).

12. Lin, M., Kim, G. H., Kim, J. H., Oh, J. W. \& Nam, J. M. Transformative heterointerface evolution and plasmonic tuning of anisotropic trimetallic nanoparticles. J. Am. Chem. Soc. 139, 10180-10183 (2017).

13. He, R. et al. Facile synthesis of pentacle gold-copper alloy nanocrystals and their plasmonic and catalytic properties. Nat. Commun. 5, 4327 (2014).

14. Chakrabarti, D. J. \& Laughlin, D. E. The Cu-S (copper-sulfur) system. J. Phase Equilibria 4, 254-271 (1983).

15. Wang, L.-W. High chalcocite $\mathrm{Cu}_{2} \mathrm{~S}$ : a solid-liquid hybrid phase. Phys. Rev. Lett. 108, 085703 (2012).

16. Hull, S. Superionics: crystal structures and conduction processes. Rep. Prog. Phys. 67, 1233-1314 (2004)

17. Freymeyer, N. J. et al. Influence of solvent reducing ability on copper sulfide crystal phase. Cryst. Growth Des. 13, 4059-4065 (2013).

18. Machani, T. et al. Synthesis of monoclinic and tetragonal chalcocite nanoparticles by iron-induced stabilization. Chem. Mater. 23, 5491-5495 (2011).

19. Turo, M. J. \& Macdonald, J. E. Crystal-bound vs surface-bound thiols on nanocrystals. ACS Nano 8, 10205-10213 (2014)

20. Robinson, E. H., Turo, M. J. \& Macdonald, J. E. Controlled surface chemistry for the directed attachment of copper(I) sulfide nanocrystals. Chem. Mater. 29, 3854-3857 (2017).

21. Zhang, Y. et al. The Size Controlled synthesis and self-assembled of monodisperse $\mathrm{Cu}_{2} \mathrm{~S}$ nanocrystals. Mater. Lett. 67, 117-120 (2012).

22. Luther, J. M., Jain, P. K., Ewers, T. \& Alivisatos, A. P. Localized surface plasmon resonances arising from free carriers in doped quantum dots. Nat. Mater. 10, 361-366 (2011). 
23. Georgieva, Z. N., Tomat, M. A., Kim, C. \& Plass, K. E. Stabilization of plasmon resonance in $\mathrm{Cu}_{2-\mathrm{x}} \mathrm{S}$ semiconductor nanoparticles. Chem. Commun. 52 , 9082-9085 (2016).

24. Lukashev, P., Lambrecht, W. R. L., Kotani, T. \& van Schilfgaarde, M. Electronic and crystal structure of $\mathrm{Cu}_{2-\mathrm{x}} \mathrm{S}$ : full-potential electronic structure calculations. Phys. Rev. B 76, 195202 (2007).

25. Wang, Y. Q., Smirani, R. \& Ross, G. G. Nanotwinning in silicon nanocrystals produced by ion implantation. Nano Lett. 4, 2041-2045 (2004).

26. Parsons, S. Introduction to twinning. Acta Crystallogr., Sect. D: Biol. Crystallogr. 59, 1995-2003 (2003).

27. Evans, H. T. Jr. Djurleite $\left(\mathrm{Cu}_{1.94} \mathrm{~S}\right)$ and low chalcocite $\left(\mathrm{Cu}_{2} \mathrm{~S}\right)$ : New crystal structure studies. Science 203, 356-358 (1979).

28. Cava, R., Reidinger, F. \& Wuensch, B. J. Mobile ion distribution and anharmonic thermal motion in fast ion conducting $\mathrm{Cu}_{2} \mathrm{~S}$. Solid State Ion. 5 501-504 (1981).

29. Evans, H. T. Jr. Crystal structure of low chalcocite. Nat. Phys. Sci. 232, 69-70 (1971).

30. Makiura, R. et al. Size-controlled stabilization of the superionic phase to room temperature in polymer-coated AgI nanoparticles. Nat. Mater. 8, 476-480 (2009).

31. Rivest, J. B. et al. Size dependence of a temperature-induced solid-solid phase transition in copper (I) sulfide. J. Chem. Phys. Lett. 2, 2402-2406 (2011).

32. Hu, T., Wittenberg, J. S. \& Lindenberg, A. M. Room-temperature stabilization of nanoscale superionic $\mathrm{Ag}_{2} \mathrm{Se}$. Nanotechnology 25, 415705 (2014).

33. Dumett Torres, D. \& Jain, P. K. Strain stabilization of superionicity in copper and lithium selenides. J. Phys. Chem. Lett. 9, 1200-1205 (2018).

34. White, S. L., Banerjee, P. \& Jain, P. K. Liquid-like cationic sub-lattice in copper selenide clusters. Nat. Commun. 8, 14514 (2017).

35. Horyatic, V., Vucic, Z. \& Milat, O. Dilatometric study of the anisotropy in the superionic cuprous selenide. J. Phys. C: Solid State Phys. 15, 957-960 (1982).

36. Heo, J., Dumett Torres, D., Banerjee, P. \& Jain, P. K. In-situ electron microscopy mapping of an order-disorder transition in a superionic conductor. Nat. Commun. 10, 1505 (2019).

37. Evans, H. T. Jr. The crystal structures of low chalcocite and djurleite. Z. für. Krist. 150, 299-320 (1979).

38. Fullman, R. L. Crystallography and interfacial free energy of noncoherent twin boundaries in copper. J. Appl. Phys. 22, 456-460 (1951).

39. Nie, A. et al. Twin boundary-assisted lithium ion transport. Nano Lett. 15, 610-615 (2015).

40. Shlomovitch, N., Bar-Matthews, M., Segev, A. \& Matthews, A. Sedimentary and epigenetic copper mineral assemblages in the Cambrian Timna Formation. Isr. J. Earth Sci. 48, 195-208 (1999).
41. Tait, K. T., Yang, H., Downs, R. T., Li, C. \& Pinch, W. W. The crystal structure of esperite, with a revised chemical formula, $\mathrm{PbCa}_{2}\left(\mathrm{ZnSiO}_{4}\right)_{3}$, isostructural with beryllonite. Am. Mineral. 95, 699-705 (2010).

\section{Acknowledgements}

Funding for this work was provided by the Energy \& Biosciences Institute (EBI) through the EBI-Shell program. This work was conducted in part at the Frederick Seitz Materials Research Laboratory. We thank the Moore group for allowing use of their DSC

instrument. We thank Zhe Zhang and David Qiu for their help in making some samples.

\section{Author contributions}

J.G. performed synthesis and characterization of materials, analysis of results, and cowriting of the paper. P.K.J. conceived project, performed analyses, theoretical modeling, and data-interpretation, and co-wrote the paper.

\section{Additional information}

Supplementary Information accompanies this paper at https://doi.org/10.1038/s41467019-11229-2.

Competing interests: The authors declare no competing interests.

Reprints and permission information is available online at http://npg.nature.com/ reprintsandpermissions/

Peer review information: Nature Communications thanks Katherine Plass, Xingchen Ye and other anonymous reviewer(s) for their contribution to the peer review of this work.

Publisher's note: Springer Nature remains neutral with regard to jurisdictional claims in published maps and institutional affiliations.

(c) (i) Open Access This article is licensed under a Creative Commons Attribution 4.0 International License, which permits use, sharing, adaptation, distribution and reproduction in any medium or format, as long as you give appropriate credit to the original author(s) and the source, provide a link to the Creative Commons license, and indicate if changes were made. The images or other third party material in this article are included in the article's Creative Commons license, unless indicated otherwise in a credit line to the material. If material is not included in the article's Creative Commons license and your intended use is not permitted by statutory regulation or exceeds the permitted use, you will need to obtain permission directly from the copyright holder. To view a copy of this license, visit http://creativecommons.org/ licenses/by/4.0/.

(C) The Author(s) 2019 